\title{
Rural and urban disparities in health-seeking for fever in Myanmar: findings from a probability-based household survey
}

\author{
Tin Aung ${ }^{1}$, Moh Moh Lwin ${ }^{1}$, May Sudhinaraset ${ }^{2}$ and Chongyi Wei ${ }^{2^{*}}$ (D)
}

\begin{abstract}
Background: The World Health Organization (WHO) recognizes Myanmar as having the highest burden of malaria in the Greater Mekong Sub-region (GMS). Early diagnosis and proper treatment are critical in containing malaria. The objective of this study was to assess determinants of seeking treatment for fever from trained providers across rural and urban areas in Eastern Myanmar.

Methods: A cross-sectional survey was conducted during the high malaria seasons in the eastern part Myanmar between August and September 2014. Multi-staged cluster sampling was used to sample households. A series of questions related to treatment-seeking for fever were asked. Bivariate and multivariate logistic regressions were conducted to identify independent correlates of seeking treatment for fever from trained providers.
\end{abstract}

Results: The analysis was restricted to 637 participants who reported either themselves or their family members having had fever 2 weeks prior to the interview. In the multivariate analysis, rural residents were less likely to have sought treatment from trained providers ( $\mathrm{AOR}=0.60,95 \% \mathrm{Cl} 0.42-0.88 ; p=0.01$ ) while residents who had fever patients between the ages of 5 and 14 years ( $A O R=1.60,95 \% \mathrm{Cl} 0.90-2.53 ; p=0.05)$; and those who knew that sleeping under bed nets can prevent malaria ( $\mathrm{AOR}=2.08,95 \% \mathrm{Cl} 1.00-4.30 ; p=0.05)$; were borderline more likely to have sought treatment.

Conclusion: This study suggests that rural populations need improved access to trained providers. Additionally, future programmes should focus on increasing knowledge around malaria prevention and treatment.

Keywords: Health disparity, Myanmar, Malaria, Health-seeking behaviour

\section{Background}

Malaria is endemic across ten countries in Southeast Asia, affecting 2.31 billion people [1]. In 2011, 2.7 million cases and over 2000 deaths were reported, where India, Indonesia, Myanmar, and Pakistan accounted for over $85 \%$ of the reported cases and deaths. In the Greater Mekong Subregion (GMS), the burden of malaria is highest in Myanmar where it remains a significant public health problem. According to the World Malaria Report country profile

\footnotetext{
*Correspondence: chongyiwei@hotmail.com

2 Department of Epidemiology and Biostatistics, University of California,

San Francisco, Mission Hall 3rd Floor, 550 16th Street, San Francisco, CA 94158, USA

Full list of author information is available at the end of the article
}

information of Myanmar, $16 \%$ of Myanmar's total population lives in high transmission areas (defined as >one case per 1000 population) [1]. Moreover, $62 \%$ of the population in the country lives in malaria-risk areas $(21.4 \%$ in high risk, $17.9 \%$ in moderate risk, $22.4 \%$ in low risk areas). According to the Myanmar National Malaria Strategic Plan 2010-2015, the number of malaria cases reported by the National Malaria Control Programme (NMCP) are only confirmed cases where diagnostic services are available [2]. There are a number of villages that still do not have access to malaria diagnosis and treatment, especially in hard-toreach areas where malaria transmission is probably the highest. In addition, there is a critical lack of data reported from the private sector and the traditional or informal 
sector. Therefore, the incidence of malaria reported by the NMCP is mostly likely an underestimate.

To prevent malaria, the World Health Organization (WHO) has emphasized that early diagnosis and prompt treatment should occur within $24 \mathrm{~h}$ of onset of symptoms to decrease risk of severe complications and onward transmission [3]. Appropriate treatment-seeking behaviour and easy access to health services are important components vital to their success [4]. Specifically, it is recommended that patients should seek medical treatment following the onset of fever, a common symptom of malaria. A few studies that examined treatment-seeking behaviour among people infected with malaria in Bangladesh reported that treatment-seeking behaviour was: associated with: socio-economic status; that children from the poorest families were least likely to seek care from trained providers [5]; proximity to health facilities [6]; accessibility to trained providers [7]; availability of transportation [8]; and, knowledge of malaria, where people who were exposed to mass media or any information sessions were more likely to seek care from trained providers $[8,9]$.

These barriers to treatment-seeking present special challenges to malaria prevention and control in Myanmar as people at the highest risk and most affected are usually rural and poor. Malaria is endemic in rural areas, where approximately $70 \%$ of Myanmar people live, including living in close proximity to forest and its fringes. Houses located within $1 \mathrm{~km}$ of the forest are at particularly high risk. Within Myanmar, the Eastern region has a high disease burden especially among children and this likely constitutes a source of infection for neighbouring regions [10]. It is important to examine health-seeking behaviour for malaria, including its symptoms (i.e., fever is one of the major symptoms of malaria in the region), among rural populations in order to develop better strategies to ensure early testing and treatment and ultimately elimination of malaria in Myanmar. In this paper, determinants of seeking treatment for fever from trained providers across rural and urban areas in Eastern Myanmar were assessed.

\section{Methods}

\section{Study location}

This study was conducted in the Eastern part of Myanmar where malaria is endemic. The study area consisted of 64 townships with an estimated six million population, where Population Services International (PSI) had worked with private sector suppliers and providers to rapidly replace widely available oral artemisinin monotherapy with highly subsidized, quality assured artemisinin-based combination therapy (ACT). At the same time, PSI had invested in massive behavioural change communications (BCC) activities, targeting both consumers and providers, which supplemented the supply chain replacement activities, with the ultimate aim of halting the spread of artemisinin-resistant Plasmodium falciparum in the region. As a part of a larger evaluation study, this survey was conducted among the 64 townships where PSI carried out the above intervention activities.

In Myanmar there are 14 states/regions, each comprised of 20-25 townships. Township level is the most common administrative unit, and there are 330 townships. A typical township consists of a small urban area/ town and vast rural area. All the township level administrative bodies and structures are situated in urban areas. Urban areas consist of three to ten wards, while rural areas consist of 15-30 village tracts. Usually the urban area of a township has one urban health centre, one township hospital, a number of general-practitioner clinics, pharmacies, and general retail shops. The rural area has one rural health center per four to five village tracts, a sub-centre (health) per village tract, many community health workers, and general retail shops.

\section{Study design and recruitment}

A cross-sectional survey was conducted during the malaria high seasons in eastern Myanmar between August and September 2014. Using multi-staged cluster sampling, 13 townships among the 64 were selected, using probability population to size (PPS). In each selected township, four wards and four village tracts were selected with PPS. In Myanmar, each township is composed of an urban area which is sub-divided into wards, and a rural area which is sub-divided into wider village tracts where an estimated $70 \%$ of population lives. The survey team mapped households in each selected township and 45 households in each cluster were selected using systematic random sampling. Among the 4680 households selected, household members or their family members who had had fever in the previous 2 weeks were interviewed. Specifically, the respondents were asked if they suspected the fever was malaria related. As malaria is well known in the study area, people generally first think of malaria whenever they have fever, especially when it is accompanied with chills and rigours. Of 640 household members who had fever, three declined interview (decline rate $=0.46 \%$ ) (Fig. 1). The respondents were the caregivers if the fever cases were under 15 years old. Trained interviewers explained the purpose of the study to each respondent and obtained verbal consent from a representative of the household, who was either the head or spouse of the head to be interviewed. When those people were not available, one of the adult members of the household was selected to be interviewed. Face-to-face interviews were conducted by trained 


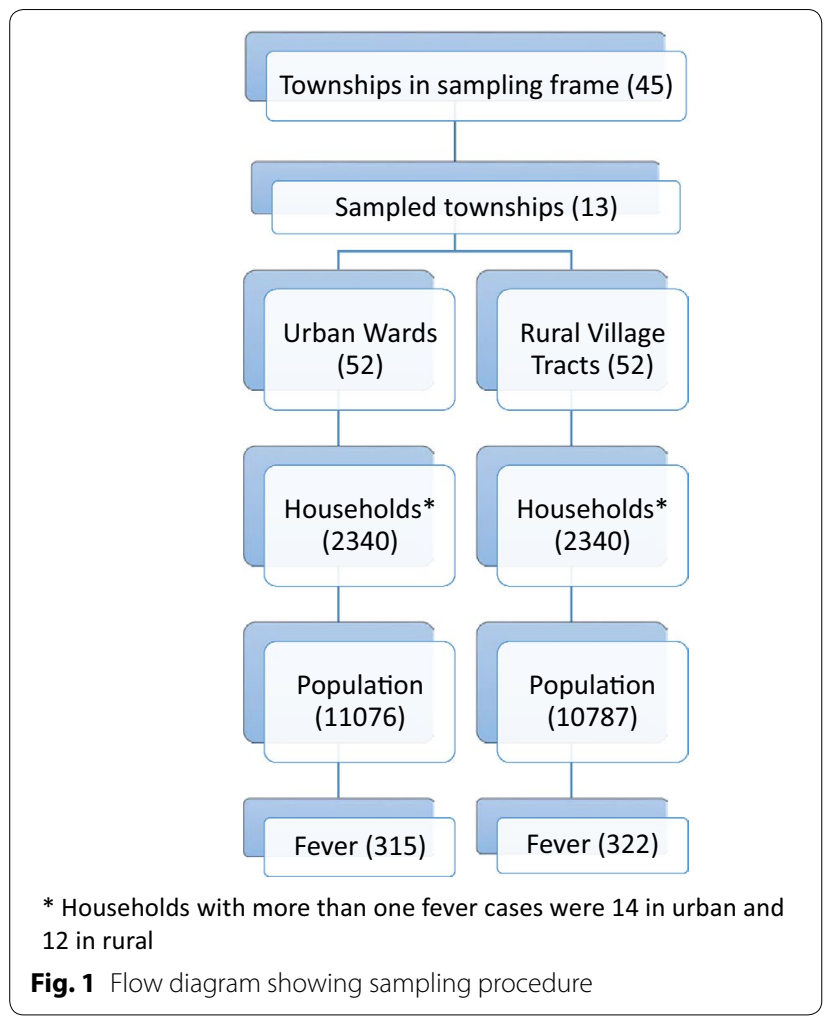

interviewers with structured questionnaires and were conducted either in Myanmar or a local language.

\section{Measures}

Demographic information, including age and gender of fever cases, education, and occupation of main household earner, and the total number of household members, was collected. Ownership of household assets was asked to calculate the wealth quintile. Questions of health-seeking behaviour for fever suspected of malaria included if and where treatment was sought, timing of seeking treatment (within vs over $24 \mathrm{~h}$ ), primary reasons of choosing providers or not seeking treatment, waiting time at provider, estimated amount of money spent for treatment, perception of provider's dealing, satisfaction with provider, and knowledge of malaria diagnosis and treatment. Respondents were also asked what types of providers they sought for themselves or their family member when they had fever. In Myanmar, the following types of facilities/providers were considered as trained: (1) public health facilities, including public hospitals, township health centres; (2) private health facilities, including health providers from worksites, general practitioners, and Sun Quality health clinics (SQH), a social, franchised network of 1400 private general practitioners' clinics in Myanmar); and (3) community health workers. Retail outlets such as pharmacies that are licensed to sell drugs, drug stores which are not licensed, grocery or village shops where people can buy drugs, and itinerate drug vendors, informal providers and 'quacks' are considered untrained.

\section{Data analysis}

CSPro software was used to enter data and the datasets were later converted to STATA version 13.0 for analysis. Chi square tests were conducted to compare differences in socio-demographic characteristics and treatment-seeking behaviour between urban and rural households. To identify independent correlates of seeking treatment for fever from trained providers, bivariate analysis was first conducted where correlates with $p$ values less than 0.2 were entered into a multivariate logistic regression model. The independent variables included in the final model were urban/rural residency, age of fever cases, education of the main household income earner, occupation of the main earner and malaria knowledge of fever cases or caregivers if the fever case happened to be under 15 years of age. The multivariate model did not include wealth quintile since it was collinear with urban/rural residency.

\section{Ethical consideration}

All respondents were informed of the purpose of the study. The respondents were fully aware that they had the right not to participate or to withdraw from the study at any time. Confidentiality was maintained at all steps of data collection. Participation was entirely voluntary and verbal consent was obtained from all respondents. The project obtained ethical approval from PSI Ethical Review Board.

\section{Results}

Between August and September 2014, 4680 households were sampled as part of a larger study, with a total of 21,861 household members. Among those, 637 (2.9 \%) respondents reported that either they or one of their family members had had fever two weeks prior to the interview. Compared to urban residents, rural residents who had had fever were more likely to be between the ages of 15 and 45 (30.8 vs $23.2 \%, p=0.033$ ) (Table 1 ). Fever patients' household characteristics differed significantly as well. Compared to urban households, rural fever patients were more likely to have a main income earner with no formal schooling ( 25.2 vs $9.5 \%, p<0.001$ ), a main income earner who was a farmer or fisherman (51.6 vs $22.5 \%, p<0.001$ ), and had lower household socio-economic status (SES) (e.g., 30.4 vs $13.3 \%$ at Level $1, p<0.001$ ). In terms of health-seeking behaviour, rural residents were less likely to have sought treatment outside of their homes ( 69.3 vs $82.2 \%, p<0.001)$ or have sought treatment within $24 \mathrm{~h}$ of fever onset $(50.9 \mathrm{vs}$ $59.4 \%, p=0.032$ ). Among those who were treated at home, rural residents were more likely to use home remedies than urban residents ( 9.0 vs $2.9 \%, p=0.001$ ). Knowledge 
Table 1 Demographic characteristics, health-seeking behaviour and health knowledge among individuals with fever 2 weeks prior to interview, Myanmar $(N=637)$

\begin{tabular}{|c|c|c|c|c|}
\hline Characteristics & Urban $(\mathrm{N}=315)$ & Rural $(\mathrm{N}=322)$ & Total $(\mathrm{N}=637)$ & $p$ value \\
\hline Age of fever cases (years) & & & & 0.033 \\
\hline Under 5 & $65(20.6)$ & $79(24.5)$ & $144(22.6)$ & \\
\hline $5-14$ & $100(31.8)$ & $84(26.1)$ & $184(28.9)$ & \\
\hline $15-45$ & $73(23.2)$ & $99(30.8)$ & $172(27.0)$ & \\
\hline 46 and above & $77(24.4)$ & $60(18.6)$ & $137(21.5)$ & \\
\hline Gender of fever cases & & & & 0.688 \\
\hline Male & $138(43.8)$ & $136(42.2)$ & $274(43.0)$ & \\
\hline Female & $177(56.2)$ & $186(57.8)$ & $363(57.0)$ & \\
\hline Education of main income earner & & & & 0.000 \\
\hline No schooling & $30(9.5)$ & $81(25.2)$ & $111(17.4)$ & \\
\hline Primary grade & $104(33.0)$ & $152(47.2)$ & $256(40.2)$ & \\
\hline Middle grade & $95(30.2)$ & $60(18.6)$ & $155(24.3)$ & \\
\hline High grade and above & $86(27.3)$ & $29(9.0)$ & $115(18.05)$ & \\
\hline Occupation of main income earner & & & & 0.000 \\
\hline Professionals/skilled workers & $38(12.1)$ & $9(2.8)$ & $47(7.4)$ & \\
\hline Farmers/fishermen & $71(22.5)$ & $166(51.6)$ & $237(37.21)$ & \\
\hline Self-employed/shop owners & $89(28.3)$ & $22(6.8)$ & $111(17.43)$ & \\
\hline Unskilled labourers & $117(37.1)$ & $125(38.8)$ & $242(38.1)$ & \\
\hline Household SES quintile & & & & 0.000 \\
\hline Level 1 & $42(13.3)$ & $98(30.4)$ & $140(22.0)$ & \\
\hline Level 2 & $43(13.7)$ & $77(23.9)$ & $120(18.8)$ & \\
\hline Level 3 & $63(20.0)$ & $79(24.5)$ & $142(22.3)$ & \\
\hline Level 4 & $72(22.9)$ & $42(13.0)$ & $114(17.9)$ & \\
\hline Level 5 & $95(30.2)$ & $26(8.1)$ & $121(19.0)$ & \\
\hline Had additional symptoms (multiple responses) & $155(24.3)$ & $130(20.4)$ & $285(44.7)$ & 0.025 \\
\hline Cough & $68(21.6)$ & $64(19.9)$ & $132(20.72)$ & 0.594 \\
\hline Aches and pains & $52(16.5)$ & $41(12.7)$ & $93(14.6)$ & 0.177 \\
\hline Sweating & $11(3.5)$ & $2(0.6)$ & $13(2.04)$ & 0.010 \\
\hline Chills & $11(3.5)$ & $17(5.3)$ & $28(4.4)$ & 0.271 \\
\hline Vomiting & $11(3.5)$ & $8(2.5)$ & $19(3.0)$ & 0.455 \\
\hline Less active & $10(3.2)$ & $8(2.5)$ & $18(2.8)$ & 0.599 \\
\hline Loss of appetite & $9(2.9)$ & $8(2.5)$ & $17(2.7)$ & 0.770 \\
\hline Treated at home & $61(19.4)$ & $98(30.4)$ & $159(25.0)$ & 0.001 \\
\hline Home remedies & $9(2.9)$ & $29(9.0)$ & $38(6.0)$ & 0.001 \\
\hline Traditional medicine & $18(5.7)$ & $21(6.5)$ & $39(6.1)$ & 0.671 \\
\hline Modern medicine & $34(10.8)$ & $48(14.9)$ & $82(12.9)$ & 0.121 \\
\hline Sought treatment outside & $259(82.2)$ & $223(69.3)$ & $482(75.7)$ & 0.000 \\
\hline Early seeking treatment & & & & 0.032 \\
\hline Sought treatment within $24 \mathrm{~h}$ of fever onset & $187(59.4)$ & $164(50.9)$ & $351(55.1)$ & \\
\hline Sought treatment $>24 \mathrm{~h}$ after fever onset & $128(40.6)$ & $158(49.1)$ & $286(44.9)$ & \\
\hline \multicolumn{5}{|l|}{ Malaria knowledge } \\
\hline Know that mosquito bite can cause malaria & $227(72.1)$ & $207(64.3)$ & $434(68.1)$ & 0.035 \\
\hline Think malaria is severe in community & $55(17.5)$ & $66(20.5)$ & $121(19.0)$ & 0.329 \\
\hline Know sleeping under bed net can prevent malaria & $16(5.1)$ & $25(7.8)$ & $41(6.4)$ & 0.167 \\
\hline Know of at least one anti-malarial drug & $60(19.1)$ & $48(14.9)$ & $108(17.0)$ & 0.164 \\
\hline Heard of rapid diagnostic testing & $49(15.6)$ & $58(18.0)$ & $107(16.8)$ & 0.407 \\
\hline
\end{tabular}


of malaria did not appear to differ significantly between urban and rural residents, except that rural residents were less likely to know that malaria is transmitted through mosquito bites (64.3 vs $72.1 \%, p=0.035)$.
Among those who sought treatment outside of their homes, urban people were more likely to seek treatment at trained providers than rural residents (65.1 vs $51.6 \%, p<0.001$ ) (Table 2). In terms of primary reasons

Table 2 Reasons for choosing providers, services received and satisfactory level to among individuals having fever two weeks prior to interview in Myanmar ( $N=637)$

\begin{tabular}{|c|c|c|c|c|}
\hline & Urban $(\mathrm{N}=315)$ & Rural $(\mathrm{N}=322)$ & Total $(\mathrm{N}=637)$ & $p$ value \\
\hline & Urban $(n=259)$ & Rural $(n=223)$ & Total $(n=482)$ & \\
\hline \multicolumn{5}{|l|}{ Sought treatment from providers } \\
\hline Provider type & & & & 0.000 \\
\hline Trained providers & $205(65.1)$ & $166(51.6)$ & $371(58.2)$ & \\
\hline Untrained providers & $54(34.9)$ & $57(48.4)$ & $111(41.8)$ & \\
\hline Primary reason for choosing provider & & & & 0.218 \\
\hline Close by/easy to reach & $158(61.0)$ & $158(70.9)$ & $316(65.6)$ & 0.783 \\
\hline Reputable quality service & $61(23.6)$ & $31(13.9)$ & $92(19.1)$ & 0.000 \\
\hline Availability of inexpensive treatment & $15(5.8)$ & $11(4.9)$ & $26(5.4)$ & 0.391 \\
\hline Availability of modern medicine & $7(2.7)$ & $6(2.7)$ & $13(2.7)$ & 0.749 \\
\hline Speed of treatment & $9(3.5)$ & $6(2.7)$ & $15(3.1)$ & 0.408 \\
\hline Can handle severe cases & $6(2.3)$ & $7(3.1)$ & $13(2.7)$ & 0.810 \\
\hline Employer arranged & $0(0.0)$ & $1(0.5)$ & $1(0.2)$ & 0.322 \\
\hline Other & $3(1.2)$ & $3(1.4)$ & $6(1.2)$ & 0.978 \\
\hline Waiting time & & & & 0.756 \\
\hline Long and very long & $38(14.7)$ & $26(11.7)$ & $64(13.3)$ & \\
\hline No or short waiting time & $221(85.3)$ & $197(88.3)$ & $418(86.7)$ & \\
\hline Perception on price & & & & 0.001 \\
\hline Very inexpensive & $68(26.3)$ & $91(40.8)$ & $159(32.9)$ & \\
\hline Somewhat inexpensive & $72(27.8)$ & $64(28.7)$ & $136(28.2)$ & \\
\hline Expensive to very expensive & $119(45.9)$ & $68(30.5)$ & $187(38.9)$ & \\
\hline \multicolumn{5}{|l|}{ Service received } \\
\hline Received test for malaria & $19(7.3)$ & $16(7.2)$ & $35(7.3)$ & 0.648 \\
\hline Received modern medicine ${ }^{a}$ & $253(97.7)$ & $217(97.3)$ & $470(97.5)$ & 0.793 \\
\hline Received antibiotic & $15(4.7)$ & $9(2.8)$ & $24(3.8)$ & 0.192 \\
\hline Received injection & $63(20)$ & $46(14.3)$ & $109(17.1)$ & 0.056 \\
\hline Provider dealing & & & & 0.302 \\
\hline Friendly and respectful & $251(96.9)$ & $215(96.4)$ & $466(96.7)$ & \\
\hline Unfriendly, rude or not sure & $8(3.1)$ & $8(3.6)$ & $16(3.3)$ & \\
\hline Overall satisfaction & & & & 0.255 \\
\hline Very satisfied & $192(74.1)$ & $177(79.4)$ & $369(76.6)$ & \\
\hline Somewhat satisfied & $61(23.6)$ & $43(19.3)$ & $104(21.6)$ & \\
\hline Dissatisfied & $5(1.9)$ & $1(0.5)$ & $6(1.2)$ & \\
\hline \multirow[t]{2}{*}{ Don't know } & $1(0.4)$ & $2(0.9)$ & $3(0.6)$ & \\
\hline & Urban $(n=56)$ & Rural (n=99) & Total $(n=155)$ & \\
\hline \multicolumn{5}{|l|}{ Reasons for not seeking treatment } \\
\hline Thought that fever is not serious & $15(26.8)$ & $25(25.3)$ & $40(25.8)$ & 0.834 \\
\hline Because fever went away & $38(67.9)$ & $72(72.7)$ & $110(71.0)$ & 0.521 \\
\hline No money for treatment & $0(0.0)$ & $4(4.04)$ & $4(2.6)$ & 0.128 \\
\hline No transportation & $1(1.8)$ & $0(0.0)$ & $1(0.7)$ & 0.182 \\
\hline The places were too far away & $1(1.8)$ & $0(0.0)$ & $1(0.7)$ & 0.182 \\
\hline Wait and see & $2(3.6)$ & $8(8.1)$ & $10(6.5)$ & 0.272 \\
\hline
\end{tabular}

a Modern medicine includes tablets, capsule syrups, injections, and antibiotics 
for choosing a provider, the most commonly cited reason for both urban and rural respondents was that providers were close by or easy to get to. However, urban people were more likely than rural residents to choose providers based on reputable quality service ( 23.6 vs $13.9 \%$, $p<0.001)$. Patients from urban households were more likely to perceive that the price spent at providers was expensive or very expensive compared to rural people ( 45.9 vs $30.5 \%, p=0.001)$. Over $90 \%$ of both urban and rural respondents reported that they felt providers treated them with respect and were friendly. Among those who did not seek treatment outside of their homes, the most commonly cited reason was that their fever went away quickly (71.5\%).

In the multivariate analysis (Table 3), rural residents were less likely to have sought treatment from trained providers $(\mathrm{AOR}=0.60,95 \% \mathrm{CI} 0.42-0.88 ; p=0.01)$ while residents who had fever patients between the ages of five and 14 years (AOR $=1.60,95 \%$ CI 0.90-2.53; $p=0.05)$ and those who knew that sleeping under bed nets can prevent malaria $(\mathrm{AOR}=2.08,95 \% \mathrm{CI}$
$1.00-4.30 ; p=0.05$ ) were borderline more likely to have sought treatment from trained providers.

\section{Discussion}

This was one of the first studies to document healthseeking for fever among rural and urban populations in Myanmar. This study provided evidence that there was a significant disparity in seeking care from trained providers between urban and rural populations in Myanmar. This could be due to the fact that a majority of health facilities are located in urban areas [11]. Furthermore, the ratio of health facilities to population size is significantly different between rural and urban areas. According to the Myanmar Health System Strengthening Review Report, there was evidence that expansion of rural health centres (RHCs) increased to $4 \%$ in 2012 compared to 2011; however, there was a downward trend in 2013 and 2014 [11]. On the other hand, hospitals in urban areas increased from 897 in 2010, 944 in 2012, to 1065 in 2014. In addition to lack of health facilities in rural areas, a significant proportion of respondents who sought treatment also

Table 3 Multivariate correlates among people who sought treatment for fever from trained providers in Myanmar $(\mathrm{N}=637)$

\begin{tabular}{|c|c|c|c|}
\hline & \multicolumn{3}{|c|}{ Sought treatment from trained providers } \\
\hline & Adjusted odds ratio & $95 \% \mathrm{Cl}$ & $p$ value \\
\hline \multicolumn{4}{|l|}{ Residence } \\
\hline Urban & 1 & & \\
\hline Rural & 0.60 & $0.42-0.88$ & 0.01 \\
\hline \multicolumn{4}{|l|}{ Age (years) } \\
\hline Under 5 & 1 & & \\
\hline $5-14$ & 1.60 & $0.90-2.53$ & 0.05 \\
\hline $15-45$ & 0.87 & $0.55-1.38$ & 0.55 \\
\hline 46 and above & 0.78 & $0.48-1.27$ & 0.32 \\
\hline \multicolumn{4}{|l|}{ Education } \\
\hline Primary grade & 1 & & \\
\hline No schooling & 1.13 & $0.70-1.82$ & 0.62 \\
\hline Middle grade & 1.09 & $0.71-1.69$ & 0.69 \\
\hline High grade and above & 1.02 & $0.61-1.73$ & 0.93 \\
\hline \multicolumn{4}{|l|}{ Occupation } \\
\hline Professionals/skilled workers & 1 & & \\
\hline Farmers/fishermen & 0.86 & $0.41-1.77$ & 0.68 \\
\hline Self-employed/shops & 1.05 & $0.50-2.20$ & 0.89 \\
\hline Unskilled labourers & 0.70 & $0.35-1.42$ & 0.33 \\
\hline \multicolumn{4}{|l|}{ Others } \\
\hline Had additional symptoms & 1.32 & $0.94-1.85$ & 0.10 \\
\hline Had known that mosquito bite can cause malaria & 1.02 & $0.71-1.46$ & 0.93 \\
\hline Think that malaria is severe disease & 0.96 & $0.63-1.46$ & 0.84 \\
\hline Know that sleeping under bed net can prevent malaria & 2.08 & $1.00-4.30$ & 0.05 \\
\hline Heard of rapid diagnostic testing & 1.22 & $0.78-1.93$ & 0.39 \\
\hline
\end{tabular}


thought that it was either expensive or very expensive. Among those who did not seek treatment outside of their homes, about a quarter thought that fever was not serious. Combined, these factors were significant barriers to accessing trained providers for rural populations and present challenges for early detection and treatment for malaria.

It was also found that those who had greater knowledge of malaria transmission and prevention were over two times more likely to seek care from trained providers than those who did not have sufficient knowledge. Nyunt et al. also found that correct knowledge on causes of malaria was associated with increased use of health care centres [9]. Future efforts should focus on improving knowledge for malaria treatment and prevention, particularly in rural areas.

Contrary to intuition, caregivers who had older children with fever (5-14 years old) were more likely to see a trained provider compared to those who had younger children with fever (under 5 years old). A potential explanation for this finding could be that younger children tended to get sick more often than older children and parents tended to wait and try with some home remedies before seeking treatment outside.

There are several limitations to this study. First, some providers might have been misclassified in the analysis. The providers were categorized into trained vs untrained as reported by individuals suffering from fever or in the case of children, the caregiver of a sick child. In actuality, respondents may not know whether the provider was formally trained or not. However, the way the provider types were categorized is well established in Myanmar. Second, this study was conducted in eastern Myanmar and may not be generalizable to populations in other parts of country. Finally, the questionnaire asked about treatment-seeking behaviour for fever suspected of being malaria and was not able to confirm that respondents were referring to malaria fever only.

\section{Conclusion}

Despite the limitations, this study demonstrated that there were significant disparities in health seeking for fever between rural and urban populations in Myanmar. The findings have important implications for malaria prevention and improving the general health among rural populations in Myanmar. First, more health centres should be established and staffed with trained health workers in rural areas. These centres should be easily accessible to the most affected groups and charge lower fees for treatment. Health workers should be trained to be able to detect malaria fever early and provide proper treatment. Second, BCC campaigns, including mass media to disseminate behavioural change messages and peer-to-peer, small-section health talks, should be ongoing and tailored to target subgroups most at risk of malaria yet who lack knowledge of malaria prevention. Finally, a holistic approach to improving the health of rural populations should be adopted where infectious diseases, such as malaria, should not be the only focus.

\section{Abbreviations \\ ACT: artemisinin-based combination therapy; BCC: behavioural change com- munications; GMS: Greater Mekong Sub-region; NMCP: National Malaria Con- trol Programme; PPS: probability population to size; PSI: Population Services International; SES: socio-economic status; RHC: rural health centre; SQH: Sun Quality health clinics; WHO: World Health Organization.}

\section{Authors' contributions}

TA conceptualized the study and led the writing of this manuscript. MML implemented the study and conducted the analysis. MS and CW oversaw the analysis and revised the manuscript. All authors read and approved the final manuscript.

\section{Author details}

${ }^{1}$ Population Services International/Myanmar, No. 16, West Shwe Gone Dine 4th Street, Bahan Township, Yangon, Myanmar. ${ }^{2}$ Department of Epidemiology and Biostatistics, University of California, San Francisco, Mission Hall 3rd Floor, 550 16th Street, San Francisco, CA 94158, USA.

\section{Acknowledgements}

We would like to thank the Department for International Development (UK), the Bill and Melinda Gates Foundation and Good Ventures for providing financial support for PSI's work on malaria (specifically Artemisinin monotherapy replacement (AMTR) project).

\section{Competing interests}

The authors declare that they have no competing interests.

\section{Availability of data and materials}

Data are available to all interested researchers upon request.

\section{Ethics approval and consent to participate}

The study was approved by the PSI Ethical Review Board. Verbal consent was obtained from all participants.

Funding

None.

Received: 19 February 2016 Accepted: 18 July 2016

Published online: 25 July 2016

\section{References}

1. WHO. World Malaria Report 2015-Regional profile and country profile information. Geneva: World Health organization; 2015.

2. Myanmar national strategic plan 2010-2015 (Unpublished report).

3. WHO. Guidelines for the treatment of malaria. World Health Organization. http://www.who.int/9789241549127_eng.pdf. Accessed 15 Feb 2016.

4. Giao PT, Vries PJ, Binh TQ, Nam NV, Kager PA. Early diagnosis and treatment of uncomplicated malaria and patterns of health seeking in Vietnam. Trop Med Int Health. 2005;10:919-25.

5. Najnin N, Bennett CM, Luby SP. Inequalities in care seeking for febrile illness of Under five children in Urban Dhaka, Bangladesh. J Health Popul Nutr. 2011;29:523-31.

6. Xu JW, Xu QZ, Liu H, Zeng YR. Malaria treatment-seeking behaviour and related factors of Wa ethnic minority in Myanmar: a cross-sectional study. Malar J. 2012;11:417. 
7. Lwin MM, Sudhinaraset M, San AK, Aung T. Improving malaria knowledge and practice in rural Myanmar through a village health worker intervention: a cross sectional study. Malar J. 2014;13:5

8. Thandar MM, Kyaw MP, Jimba M, Yasuoka J. Caregivers'treatment-seeking behaviour for children under age five in malaria-endemic areas of rural Myanmar: a cross-sectional study. Malar J. 2015;14:1.

9. Nyunt MH, Aye KM, Kyaw MP, Wai KT, Oo T, Than A, et al. Evaluation of the behavior change communication and community mobilization activities in Myanmar artemisinin resistance zones. Malar J. 2015;14:522.
10. Richards AK, Smith L, Mullany LC, Lee Cl, Whichard E, Banek K, et al. Prevalence of Plasmodium falciparum in active conflict areas of eastern Burma: a summary of cross-sectional data. Confl Health. 2007;1:9.

11. Sein TT, Myint P, Tin N, Win H, Aye SS, ST. The republic of the union of Myanmar health system review. Health Syst Transit. 2014;4:3.

\section{Submit your next manuscript to BioMed Central and we will help you at every step:}

- We accept pre-submission inquiries

- Our selector tool helps you to find the most relevant journal

- We provide round the clock customer support

- Convenient online submission

- Thorough peer review

- Inclusion in PubMed and all major indexing services

- Maximum visibility for your research

Submit your manuscript at

www.biomedcentral com/submit 